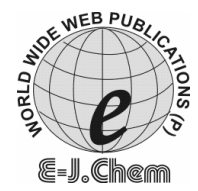

\title{
Preparation and Antimicrobial Activity of $s$-Triazine Hydrazones of 7-Hydroxy Coumarin and their Metal Complexes
}

\author{
G. R. JANI*, K. B. VYAS and ZUDAS FRANCO ${ }^{\S}$ \\ *Department of Chemistry, M.N.College,Visnagar-384315 (Gujarat), India. \\ Department of Chemistry, Govt. Science College, Sector-15,Gandhinagar (Gujarat), India. \\ ${ }^{\S}$ Department of Chemistry, Sheth R.A Bhavan's Science College, \\ Khanpur, Ahmedabad (Gujarat), India. \\ jani_sunil13@yahoo.com
}

Received 22 February 2009; Accepted 4 April 2009

\begin{abstract}
Metal complexes of 7-hydroxy coumarin hydrazone of $s$-triazine derivatives derived from 7-hydroxy-8-aceto- $N$-(4',6'-dichloro-1', 3', 5'-striazine) coumarin hydrazone and transition metals have been synthesized and screened for their antibacterial, antifungal and antiseptic activity. The geometry of the complexes has been proposed. The ligand system co-ordinates with the metal ion in a bidentate manner through the nitrogen atom of hydrazone group.
\end{abstract}

Keywords: Coumarin, Hydrazone, Metal complexes, Antibacterial activity, Antifungal activity.

\section{Introduction}

Coumarins are naturally occurring compounds which are known to have biological activities ${ }^{1}$. Some coumarin derivatives possessing carboxamide moiety are found to have diuretic, analgesic myorelaxant ${ }^{2}$, antifungal ${ }^{3}$ and anthelmintic activities ${ }^{4}$. It is suggested that the compounds having antimicrobial activity may act either by killing the microbe or blocking their active site ${ }^{5-7}$.

The literature survey reveals that no work has been done on the antimicrobial, antiseptic effect of this hydrazone $s$-triazine derivative of 7-hydroxy coumarin and it's metal complexes. Hence, this paper reports the synthesis and antibacterial, antifungal activity of 7 hydroxy-8-aceto- $N$-(4',6'-dichloro-1',3',5'-s-triazine) coumarin hydrazones of coumarin ligand and its metal(II) complexes to know whether these biological activity of the ligand is enhanced by the presence of metal ion upon coordination.

\section{Experimental}

All chemicals used were of analytical grade (E.Merck,India) Melting point of the complexes were determined using Thomas Hoover apparatus, IR Spectra were recorded using 
Shimadzu 435 FT IR Spectrophtometer by $\mathrm{KBr}$ technique. Elemental analysis was done using CARLO ERBA 1106 Micro analyser.

Chelation of metal ions using 7-hydroxy-8-aceto-N-(4',6'-dichloro-1',3',5', -s- triazine)coumarin hydrazone

$1 \%$ Ethanolic solution of 7-hydroxy-8-aceto- $N$-(4',6' - dichloro-1', $3^{\prime}, 5^{\prime}-s$ - triazino) coumarin hydrazone was added drop wise to a warm cupric chloride solution maintaining the $\mathrm{pH}$ of the mixture at $\mathrm{pH} 4.5$ during the reaction. Light green precipitates were formed. Precipitates thus obtained were washed with warm ethanol. The precipitates are soluble in benzene and acetone. The melting point of bis[7-hydroxy-8-aceto- $N$-(4',6'-dichloro-1',3',5'-s-triazino) coumarin hydrazone] copper is $262{ }^{\circ} \mathrm{C}$.

Similarly other metal complexes were prepared. The elemental analyses data are summarized in Table 1.

Table 1. Chelates with 7-hydroxy-8-aceto- $N$-(4'6'-dichloro 1',3',5'-s-triazino)coumarin hydrazone (Figures in bracket resembles theoretical values in the table).

\begin{tabular}{cccccccc}
\hline Mol. & Mol. & \multicolumn{7}{c}{ \% of Elements } \\
\cline { 3 - 8 } Formula & Wt & \multicolumn{7}{c}{$\mathrm{C}$} & $\mathrm{H}$ & $(\mathrm{O})$ & $\mathrm{N}$ & $\mathrm{Cl}$ \\
\hline $\mathrm{Cu}\left(\mathrm{C}_{14} \mathrm{H}_{8} \mathrm{O}_{3} \mathrm{~N}_{5} \mathrm{Cl}_{2}\right)_{2}$ & 793.5 & $\mathrm{Cu} 8$ & 42.33 & 2.0 & 12.07 & 17.65 & 17.88 \\
& & $(8.00)$ & $(42.34)$ & $(2.01)$ & $(12.09)$ & $(17.64)$ & $(17.89)$ \\
$\mathrm{Ni}\left(\mathrm{C}_{14} \mathrm{H}_{8} \mathrm{O}_{3} \mathrm{~N}_{5} \mathrm{Cl}_{2}\right)_{2}$ & 788.71 & $\mathrm{Ni} \mathrm{7.46}$ & 42.56 & 2.01 & 12.14 & 17.76 & 17.96 \\
& & $(7.47)$ & $(42.58)$ & $(2.02)$ & $(12.16)$ & $(17.74)$ & $(17.99)$ \\
$\mathrm{Co}\left(\mathrm{C}_{14} \mathrm{H}_{8} \mathrm{O}_{3} \mathrm{~N}_{5} \mathrm{Cl}_{2}\right)_{2}$ & 788.94 & $\mathrm{Co} 7.56$ & 42.55 & 2.02 & 12.15 & 17.70 & 17.98 \\
& & $(7.57)$ & $(42.54)$ & $(2.02)$ & $(12.15)$ & $(17.72)$ & $(17.97)$ \\
$\mathrm{Fe}\left(\mathrm{C}_{14} \mathrm{H}_{8} \mathrm{O}_{3} \mathrm{~N}_{5} \mathrm{Cl}_{2}\right)_{2}$ & 420.85 & $\mathrm{Fe} \mathrm{13.31}$ & 39.86 & 1.89 & 11.37 & 16.61 & 16.88 \\
& & $(13.32)$ & $(39.89)$ & $(1.89)$ & $(11.39)$ & $(16.62)$ & $(16.86)$ \\
\hline
\end{tabular}

The FT IR spectra were recorded in the range of O-H stretching band at $3650-3400 \mathrm{~cm}^{-1}$. IR spectra of all the complexes exhibit a broad band around $3270 \mathrm{~cm}^{-1}$ and a sharp peak in that range. These peaks can be assigned to $-\mathrm{OH}$ stretching and bending vibration, which indicates the presence of coordinated water molecule in the complexes

The ligand band at $3370 \mathrm{~cm}^{-1}$ corresponding to $-\mathrm{NH}$ has been shifted to $\pm 25-40 \mathrm{~cm}^{-1}$ in the complexes, which indicates the coordination of metal and ligand through nitrogen atom ${ }^{8}$. The ligand band at $1070 \mathrm{~cm}^{-1}$ corresponding to $-\mathrm{C}-\mathrm{O}-\mathrm{C}$ has been shifted to $\pm 25-35 \mathrm{~cm}^{-1}$ in the complexes, which indicates the coordination through oxygen atom ${ }^{9}$.

\section{Antibacterial activity}

The antibacterial activity of the compounds was tested by paper method (also called as agar diffusion method) as described by Bryant ${ }^{10}$. For bacterial activity nutrient agar was used.

The culture of above organism was prepared in distilled water. Then culture was poured over the surface of the media under sterile condition and then it was allowed to stand for few minutes and then remaining culture was drained off from media and dried. $5 \mathrm{~mm}$ diameter paper discs were prepared and were sterilized in autoclave after dipping the disc in the suspension of the compounds. They were dried to remove the remaining alcohol.

Then these paper discs were put in Petri dish containing culture coated media The paper discs were allowed to settle on media and then all the Petri dishes were incubated for 20 to 24 hours at $37{ }^{\circ} \mathrm{C}$ after incubation the zone of inhibition was measured. 


\section{Antifungal activity}

The fungi used as test organisms is Aspergillus niger. The fungi was grown on slants for 4 to 5 days till maximum sporulation was observed. The spore suspension was prepared by adding 5 to $8 \mathrm{~mL}$ of sterile distilled water in the slants and scraping with nicrome wireloop. The spores suspension was poured on the surface of the media in Petri dish. The testing compounds were taken in cups at concentration of $10 \mathrm{~mL}$ per cup with appropriate solvent control. The plates were then incubated at $37{ }^{\circ} \mathrm{C}$ for 24 to 48 hours and sensitivity reading was recorded (zone of inhibition). Antimicrobial activity is represented in Table 2.

Table 2. Antimicrobial activity of compounds.

\begin{tabular}{|c|c|c|c|c|c|c|}
\hline \multirow[b]{2}{*}{ S No. } & \multirow[b]{2}{*}{ Name } & \multicolumn{5}{|c|}{ Zone of inhibition } \\
\hline & & 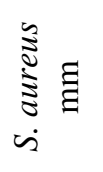 &  & 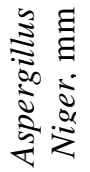 & 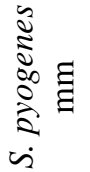 & 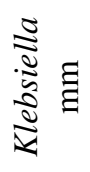 \\
\hline 1. & $\begin{array}{l}\text { Bis[7-hydroxy-8-aceto-N-(4',6'-dichloro-1',3',5'- } \\
s \text {-triazone) coumarin hydrazone] copper(II) }\end{array}$ & 3.47 & 1.15 & 4.6 & 2.9 & 0.00 \\
\hline 2. & $\begin{array}{l}\text { Bis[7-hydroxy-8-aceto-N-(4',6'-dichloro-1',3',5'- } \\
s \text {-triazone) coumarin hydrazone] nickel(II) }\end{array}$ & 0.57 & 0.57 & 1.15 & 0.57 & 0.00 \\
\hline 3. & $\begin{array}{l}\text { Bis[7-hydroxy-8-aceto-N-(4',6'-dichloro-1', } 3^{\prime}, 5^{\prime} \text { - } \\
s \text {-triazone) coumarin hydrazone] cobalt(II) }\end{array}$ & 0.81 & 0.57 & 0.34 & 2.5 & 0.00 \\
\hline 4. & $\begin{array}{l}\text { Bis[7-hydroxy-8-aceto- } N \text {-(4',6'-dichloro-1', } 3^{\prime}, 5^{\prime} \text { - } \\
s \text {-triazone) coumarin hydrazone] ferrous(II) }\end{array}$ & 1.72 & 1.14 & 2.30 & 1.14 & 0.00 \\
\hline 5. & $\begin{array}{l}\text { Bis[7-hydroxy-8-aceto- } N \text {-(4',6'-dichloro-1',3',5'- } \\
s \text {-triazone) coumarin hydrazone] ferrous(III) }\end{array}$ & 1.72 & 0.57 & 1.80 & 0.57 & 0.00 \\
\hline
\end{tabular}

The cultures used for the bacterioststic study were as follow:

i) Escherchia coli and staphylococcus aureus for antibacterial activity,

ii) Streptococcus pyogenes and P. klebsiella for antiseptic activity and

iii) Aspergilius niger for antifungal activity

Some drugs taken for comparison are garamycin, ampicillin, penicillin and chloramphenicol. The synthesized compounds were used for study and their activity measured in terms of zones of inhibition given in the Table 3 .

\section{Results and Discussion}

All parameters which we have discussed above are in well agreement with given structure (Scheme 1).



7-Hydroxy-8-aceto-coumarin hydrazone

$$
\downarrow \begin{aligned}
& \text { Cyanuric chloride } \\
& \text { refluxed, } 3 \mathrm{~h} \text { at } 5{ }^{\circ} \mathrm{C}
\end{aligned}
$$




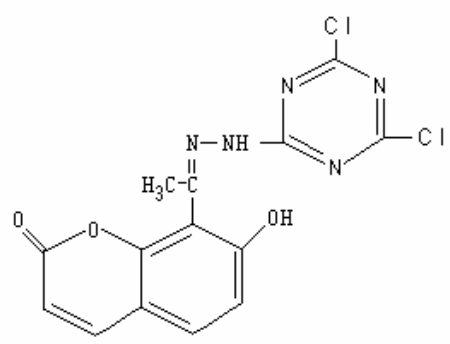

7-Hydroxy-8-aceto- $N$-[4',6', dichloro-1', 3', 5'-s-triazino coumarin hydrazone.

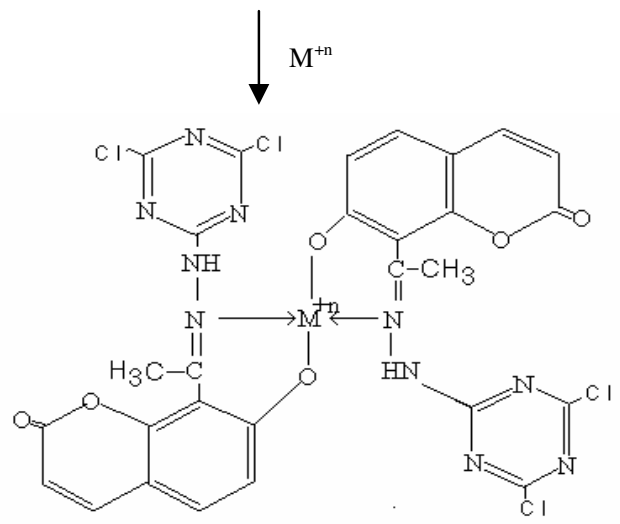

Scheme 1. Hydrazone and their chelates.

The antimicrobial activity data clearly illuatrates that the metal complexes have significant antibacterial and antifungal activity against tested organism.

From Table 2, It can be concluded that the $\mathrm{Cu}(\mathrm{II}), \mathrm{Fe}(\mathrm{II})$ and $\mathrm{Fe}(\mathrm{III})$ complexes showed higher activity where the other complexes have moderate activity. It is clear that all the compounds have displayed maximum activity against $S$. aureus

Table 3. Zone of inhibition against standard drugs.

\begin{tabular}{lcccc}
\hline Culture & $\begin{array}{c}\text { Geramycin } \\
\mathrm{mm}\end{array}$ & $\begin{array}{c}\text { Ampicillin } \\
\mathrm{mm}\end{array}$ & $\begin{array}{c}\text { Penicillin } \\
\mathrm{mm}\end{array}$ & $\begin{array}{c}\text { Chloramphenicol } \\
\mathrm{mm}\end{array}$ \\
\hline E. coli & 6.00 & - & - & - \\
S. aureus & - & 5.00 & - & - \\
S. pyogenus & - & - & 5.00 & - \\
P.Klebsiella & - & - & - & 6.00 \\
A. niger & - & - & 6.00 & - \\
\hline
\end{tabular}

\section{Acknowledgement}

Authors thank Department of Chemistry, M.N.College,Visnagar, for providing the necessary facilities to carry out this research work. Authors also thank Gittar Laboratory Ahmedabad, for providing IR Spectral data.

\section{References}

1. Agarwal M, Bansal S B and Singhal O P, J Indian Chem Soc., 1981, 58, 206.

2. Bonsignore L, Loy G, Seci D and Calignano A, Eur J Med Chem., 1993, 28, 517. 
3. Shah S and Mehta R H, J Indian Chem Soc., 1987, 64, 708.

4. Clotheir M F and Byunghyun L, Chem Abstr., 1992, 117, 787.

5. Figgis B N and Nyholm R S, J Chem Soc., 1958, 4190.

6. Cotton F A and Wilkinson G, Advanced Inorganic Chemistry, Interscience Publishers, 1962.

7. Mishra L K, Jhay Sinha B K, Kant R and Singh R, J Indian Chem Soc., 1999, 76, 65.

8. Samy M Abu-El-wafa, Raafat M Issa and Abd-El-Reheem M EI- Dekkin, Indian J Chem., 1990, 29A, 285.

9. Colthup N B, J Opt Soc Am., 1950, 40, 397.

10. Bryant M C, Antibiotics and their Laboratory Control, Butterworth, London, 1968, 26. 


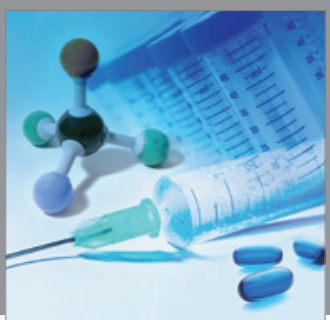

International Journal of

Medicinal Chemistry

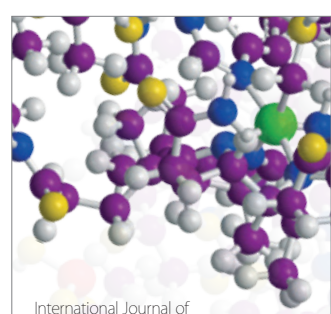

Carbohydrate Chemistry

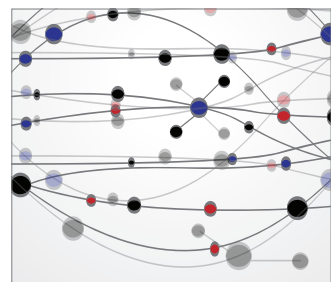

The Scientific World Journal
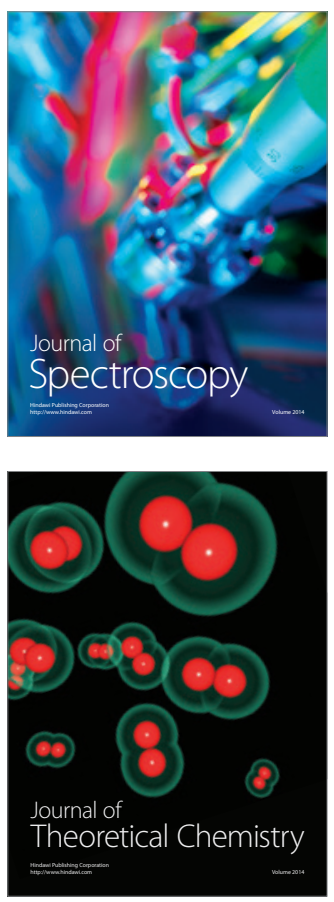
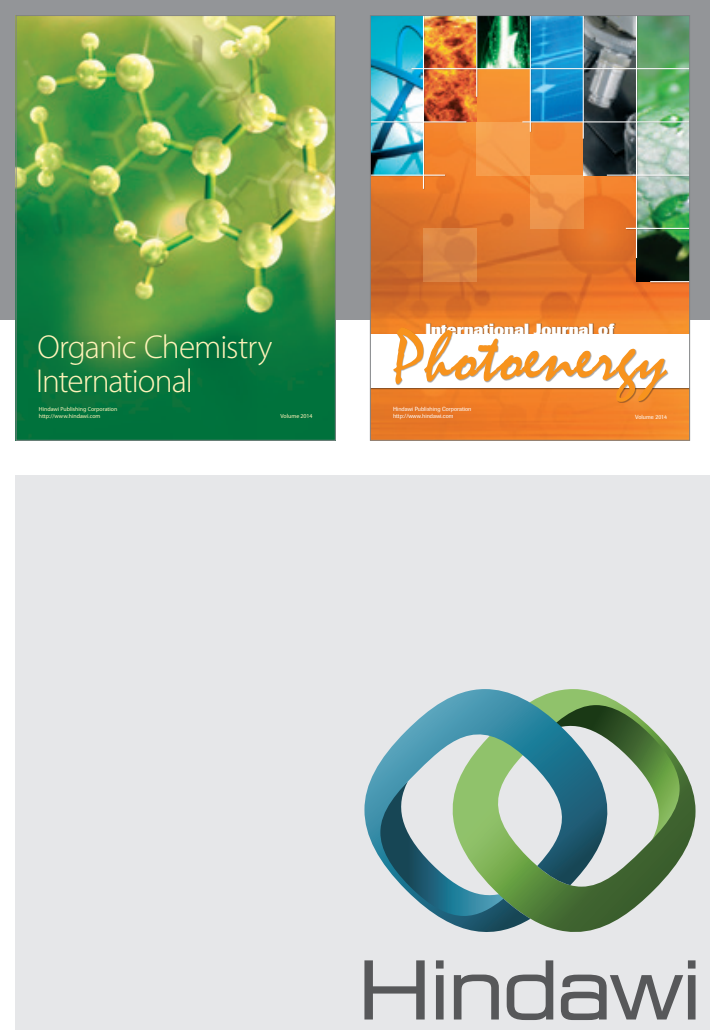

Submit your manuscripts at

http://www.hindawi.com
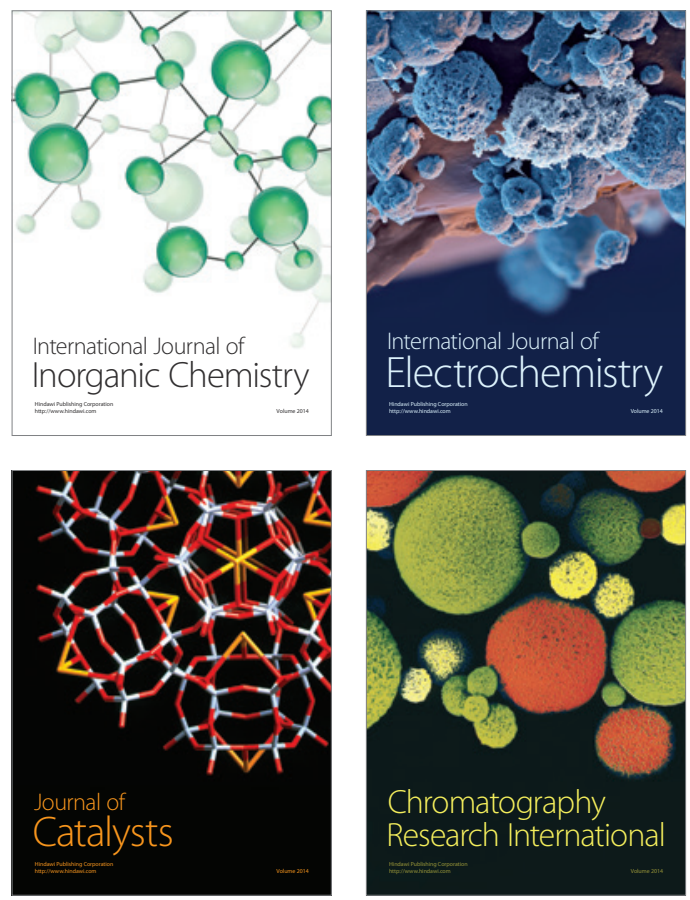
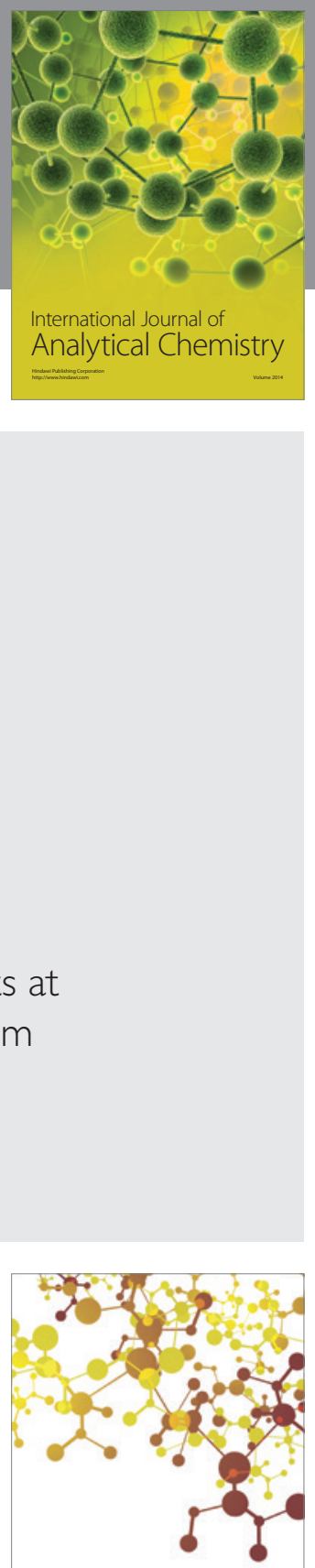

Journal of

Applied Chemistry
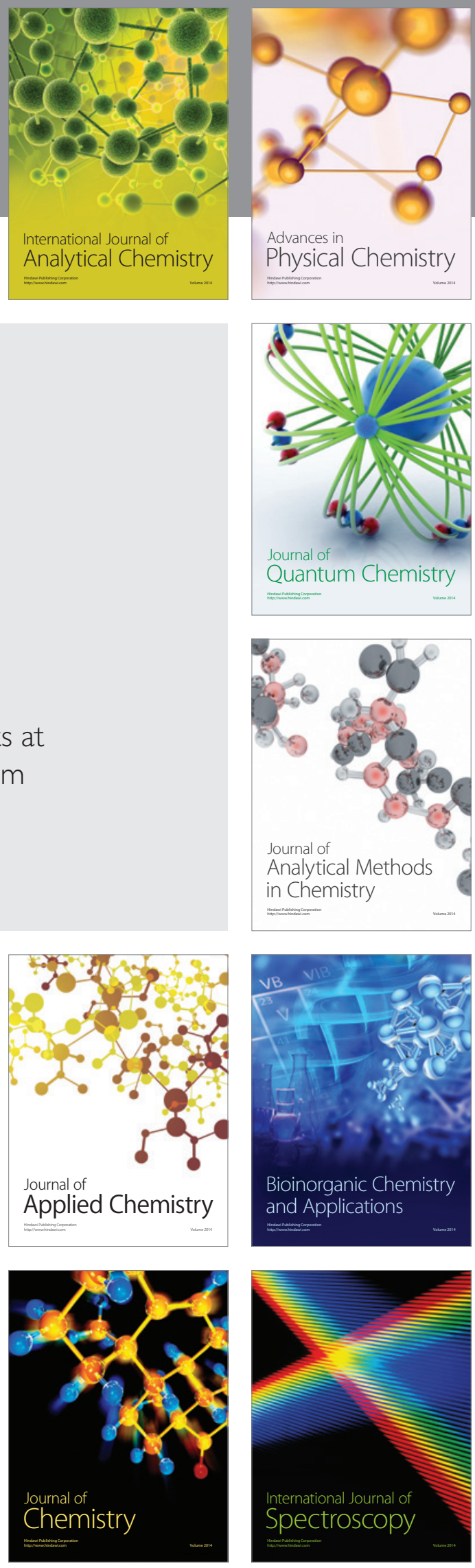